\title{
Escape Behavior of Suspects Following Acts of Crime and Warrant Issuances: A Study towards the Development of Warranted Suspect Tracing Innovation
}

\author{
Jirabhop Bhuridej $^{1}$, Peraphon Sophatsathit ${ }^{1}$ \& Achara Chandrachai ${ }^{1}$ \\ ${ }^{1}$ Technopreneurship and Innovation Management, Chulalongkorn University, Bangkok, Thailand \\ Correspondence: Jirabhop Bhuridej, Technopreneurship and Innovation Management, Chulalongkorn University, \\ Bangkok, Thailand. Tel: 66-8-1563-4444. E-mail: jirabhop@gmail.com
}

Received: June 9, 2014 Accepted: August 2, 2014 Online Published: August 22, 2014

doi:10.5539/ass.v10n18p137 URL: http://dx.doi.org/10.5539/ass.v10n18p137

\begin{abstract}
The study of escape bahaviour of warranted suspected involves Qualitative Research by means of in-depth interviews of individual with experiences and expertise in tracing warranted suspects in order to analyse the escape behaviour of warranted suspects in order to find out where they fled to following acts of crime. The study found that there were different factors affecting escape behavior such as suspect financial position, suspect background, suspect demeanor, severity of crime, past crime history, and geography. The experts have opined that "the main point about escape behaviour is not how the suspects escape, but how they live their lives following the acts of crime". The most important information leading to suspect arrests is social security information which details his new occupation. The second most important is the suspect's financial activities, with the third being his telephone usage and other service records like medical care, utilities, electricity, water, food order, as well as cable TV viewing having secondary significance. Meanwhile, the main obstacles associated with the arrests of warranted suspects are the insufficient number of investigators and the lack of the application of relevant technologies to facilitate the officers' operations. The researcher therefore suggests that all the data relevant to investigation should be linked nationwide via technology to help with the arrests of suspects. This research has resulted in a new body of knowledge in tracing warranted suspects, the result of which can be developed further into the warranted suspects tracing system. By doing so, the effectiveness and capacity of the police in arresting warranted suspects will be enhanced.
\end{abstract}

Keyword: innovation, crime, warranted suspect, royal Thai police

\section{Introduction}

Crime is a severe problem and the so-called "scourge of the society". It directly affects the safety of the citizens as well as social order in general. Currently, crime problems are associated with social and technological advanced as seen by rising crime figure. For example, from 2007-2011, the number of cases where the state is a victim increased by more than 20 percent (Central Information Technology Centre, 2013). Not only the number of cases has increased, but also the various and more complicated ways in which crime has been committed. Even though every single government has realised the severity of crime and the police has worked to the best of their ability in trying to bring suspected criminal to justice in an effort to maintain peace and protect the lives and properties of citizens, there still remain some criminals on the run. This is reflected in the number of accumulated warrants whereby. For example, in 2009 there were 38,208 such warrants, but the number increased to 45,845 the following year. Currently, there are a total of 152,148 warrants left in the Royal Thai Police database as of 28 March 2013. (Central Information Technology Centre, Royal Thai Police 2013) Even though senior officials in the Royal Thai Police has repeatedly urged police officers in each precinct to arrest warranted suspects, the number of accrued warrant has still not significantly dropped. According to the Criminal Records Division, Royal Thai Police, in 2011, there are a total of 550,169 criminal cases with 45,845 warrants issued. The arrest was made in 16,167 cases or 35.26 percent. (excluding abandoned cases and prescription) In 2010 there are a total of 39,944 warrants issued, with the arrest being made in 11,371 cases or 41.23 percent. (excluding abandoned cases and prescription) In 2009 there are a total of 38,308 warrants issued, with the arrest being made in 9,639 cases or 34.74 percent. (excluding abandoned cases and prescription) (Royal Thai Police 2013) This shows that officers can arrest approximately a third of suspected warrants, with the remainder posing 
threats to the society in one way or another. Thanks to the importance of this problem, a study was conducted to develop warrant-related process of the Royal Thai Police. To this end, the analytical and synthetic investigation methods of experts and past successful investigation methods will be analysed to determine the escape behaviour of suspects following acts of crime and warrant issuances, which in turn leads to more efficient arrest of suspects. The product of this research is the likelihood and possible areas where suspect may be in hiding, which will help narrow down the area of investigation, in turn enabling the officer to make more timely and objective arrests.

\section{Method}

This study involves Qualitative Research by means of in-depth interviews of ten investigators of the Royal Thai Police with considerable expertise in investigation in order to find out about the escape behaviour of suspects following acts of crime and warrant issuances, the methods and success factors in tracing warranted suspects, and the problems associated with arresting suspects with accrued warrants. The details of each expert are as followed.

Table 1. Experts

\begin{tabular}{|c|c|}
\hline Order & Position \\
\hline Expert 1 & $\begin{array}{l}\text { Political Deputy Secretary to the Prime Minister. Former Deputy Commissioner General, Royal } \\
\text { Thai Police. Former Advisor Commissioned Officer } 10(\mathrm{CO} 10)\end{array}$ \\
\hline Expert 2 & $\begin{array}{l}\text { Advisor Commissioned Officer } 10 \text { (CO 10). Former Deputy Commissioner General, Royal Thai } \\
\text { Police. }\end{array}$ \\
\hline Expert 3 & Deputy Commissioner, Metropolitan Police Bureau \\
\hline Expert 4 & Superintendent, Marine Police Division \\
\hline Expert 5 & Investigation Superintendent, General Staff Division, Samut Prakarn Provincial Police \\
\hline Expert 6 & $\begin{array}{l}\text { Superintendent, Technology Crime Investigation and Analysis Group, Information Technology } \\
\text { Support Division, Office of Information and Communication Technology }\end{array}$ \\
\hline Expert 7 & Deputy Operational Superintendent 10, Children, Juvenile and Women Division \\
\hline Expert 8 & Inspector, Technology Crime Suppression Division \\
\hline Expert 9 & Operational Inspector 8, Crime Suppression Division \\
\hline Expert 10 & Investigation Inspector, Cheong Talay, Phuket Provincial Police \\
\hline
\end{tabular}

\section{Results}

\subsection{Initial Experiment Results}

Escape behavior of suspects following acts of crime differs for each individual. After interview ten experts with extensive background (at least 10 years' worth of experience) in investigating and arresting suspects, the escape behaviour can be summed up as follows. First, there is a relationship between escape behaviour and type of offence. All ten experts agreed that in high severity crime such as murder or high-punishment crime, the suspects generally tend to hide their demeanor and address, be constantly on the move and escape to unpredictable destinations, possibly abroad or areas in which the suspects have never lived. They may also escape to the abode of trusted individual where they can life in relative safety. In contrast, suspects who commit offences against property tend not to be aware that they were issued warrants, and thus will repeat offences in the same or nearby areas, which means the criminals can be easily located. According to Investigation Inspector, Cheong Talay, Phuket Provincial Police, when a suspect who committed serious crime such as murder knows that a warrant has been issued against him, he will escaped from his usual place and possibly resign from his current job. In contrast, there are a number of petty suspects who are unaware that warrants have been issued against them and thus will continue to live their lives normally. Second, there is a relationship between escape behaviour and the time gap between act of crime and warrant issuance. Expert 2, Advisor Commissioned Officer 10 (CO 10) and former Deputy Commissioner General, Royal Thai Police, stated that shortly after the act of crime, a suspect would try to escape once he knew he had been issued warrant. After a while, when no actual arrests has been made, he will resume his normal life. Expert 9, Operational Inspector 8, Crime Suppression Division also agreed, saying that the longer the warrant posted, the easier it is to arrest suspects, especially in cases near prescription as suspect will return to live unguarded in his hometown. Third, suspect lifestyle is more important than his 
escape behaviour. This is the most important issue which was agreed by all the experts. The reason being, it is more difficult to define the escape behaviour as it depends upon scene of crime, timing, and opportunity. However, it is the lifestyle of the suspect which will be the main factor in successfully arresting suspects on the run. The viewpoint of the experts in the three aforementioned key points can be summed up in the form of Figure 1 , depicting escape behaviour of suspects.

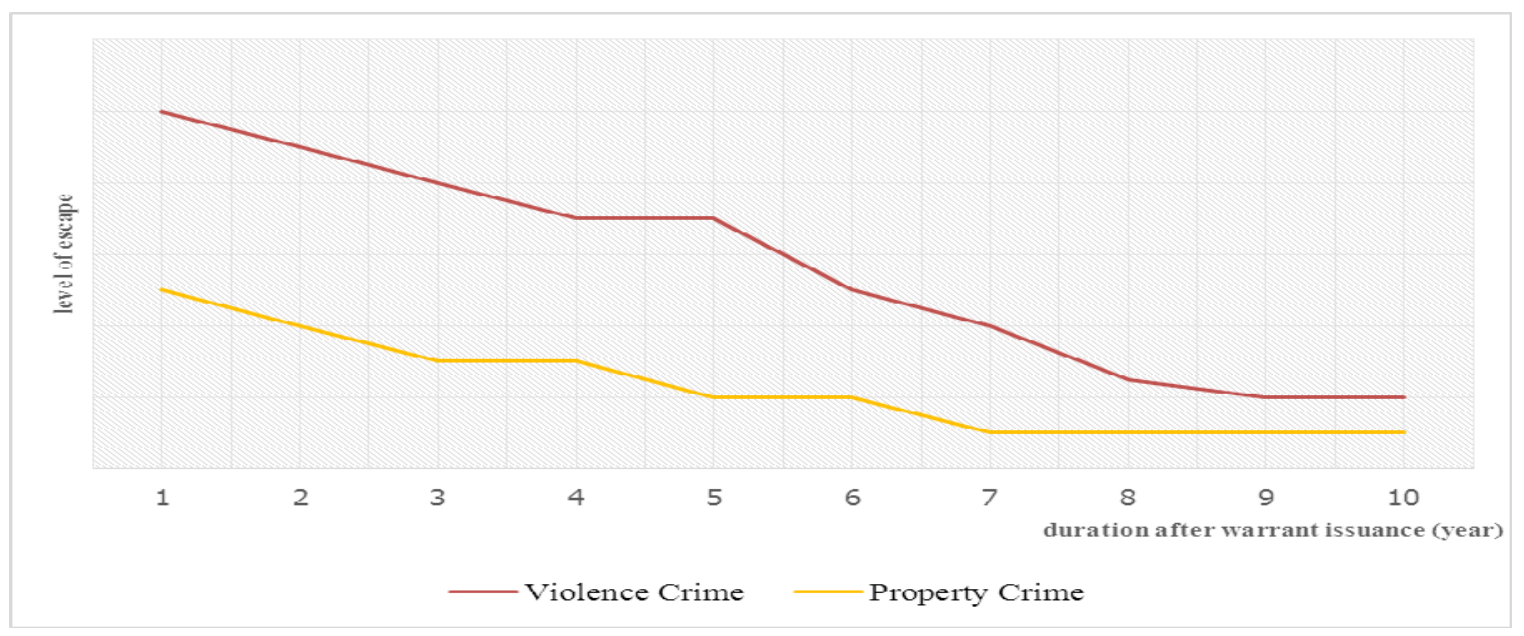

Figure 1. Escape behaviour of suspects following acts of crime

\subsection{Methods and Success Factors in Tracing Warranted Suspects}

Each interviewed expert described different methods and success factors in tracing warranted suspect, depending upon his experience and expertise. In terms of experience, the researcher chose only experts with at least 10 years' worth of experience in investigating position. Apart from number of years at the tenure, much depends on the number of actual cases handled by the experts and the characteristics of cases. For example some experts may have considerable experiences in pursuing serious cases or suspects of severe offence such as Expert 9, whereas some may be more adept at handling general offence especially those who worked at a provincial level. Another important point is that each expert's individual skills pertain to his age or background. For example, elderly experts are normally lacking when it comes to investigation technology. They made up for this deficit with communication skills with the locals thanks to their prestige acquired from lengthy tenure, making it easier for them to access information from the community regarding suspects. In investigator terms, this skill is dubbed "ground investigation". At the other end, younger investigators will be adept with usage of technology in tracking down suspects, often relying on database search on computer, online social media, and telephone usage to achieve their mission. In investigator terms, this method is called "air investigation". Due to there being two distinct investigation skill sets, the researcher has chosen a mix of experts to cover those who specialize in ground investigation and air investigation, or both, in order to obtain in-depth information regarding the tracing of warranted suspects.

Expert 5, Investigation Superintendent, General Staff Division, Samut Prakarn Provincial Police who is an expert in both ground and air investigation, stated that the first thing to keep in mind when an officer is to commence an investigation on warranted suspect is to make sure that the warrant has not expired, and the suspect is yet to be apprehended. In practice, if the suspect is arrested based on expired warrant or he or she has been arrested but the warrant has not yet been removed from the system, it will be damaging to both the arrester and the arrested. Therefore, meticulous research should be made on the warrant before commencing investigation. The next step is to look up suspect information via Police Information System (POLIS). Expert 6, Superintendent, Technology Crime Investigation and Analysis Group, Information Technology Support Division, Office of Information and Communication Technology, Royal Thai Police, a widely respected air investigator among officers, described that POLIS is the system which allows police officers to conduct extensive search of suspect information. Data such as hometown information, home address according to identification card, name of spouse, parents, children, cars in ownership, firearms owned, past criminal records can be looked up in detail. Therefore, one should prioritize the POLIS search so as to obtain as much essential data as possible. More importantly, the investigator should input the identification number of the suspect as sometimes there may be more than one instance of that suspect's name. Every expert agrees that POLIS has greatly assisted police officers in searching 
for key information on suspects. One such information is household registration data, which will allow the officer to determine the suspect's hometown, current address, parents' identity, appearances, markings, height, not to mention vehicles and firearms under his ownership and past criminal records as well as the number of warrants issued against him. All of this data will prove useful in arresting suspects. The next step is the internet search. Expert 8, Inspector, Technology Crime Suppression Division and Expert 6, Superintendent, Technology Crime Investigation and Analysis Group, Information Technology Support Division, Office of Information and Communication Technology, Royal Thai Police, the two air investigation experts, both mentioned that the internet search, especially social media, which is popular among younger generations, deeming another necessary source of data. Among the more convenient search channels are Google and Facebook. By search a suspect's name on these sites, one may find relevant information which leads to eventual arrests. However, some experts found that certain suspects may alter their personal information after warrant issuance, which may affect the validity of such information. Even then, online information should not be overlooked. Expert 8 suggested that by searching the surname of the suspect, an officer may find additional data such as the information on a suspect's close friends, relatives, and family members, which can possibly link to the suspect himself. Another possible source of social media data is Line, the mobile chat application. Currently, while it is not possible to search a suspect's real name in the application, if his mobile number can be obtained, his or her line account (if available) will appear, offering yet another unexplored source of personal data.

Of secondary importance is the data not found in POLIS and on the internet. The experts all agreed that such data can only be obtained via personal relations since it has yet to be incorporated within the Royal Thai Police database. For example information on a suspect's intimate individual, insurance data, financial information, and telephone usage. Expert 2, regarded as the legendary "ground investigator" within the Royal Thai Police emphasized that prestige is one of the most quintessential qualities of an investigator, as possessing one leads faith and trust among the informants. Having prestige can also make or break an investigation, as a prestigious investigator who has gained community trust will be able to obtain necessary information much more easily. Building prestige however, is completely different from studying conventional subjects like mathematics history, or science, as doing so has no fixed pattern. To make a successful investigation, an officer needs to learn art of finding information as well use his talent and personal technique in order to reach the suspect.

Another essential set of data an investigator needs to obtain when he conducts field investigation is the so-called sourced data which includes information acquired from a suspect's relatives. Even though such information may have little credibility if the suspect enjoys a cordial relationship with his relatives, resulting in them helping to conceal information on his whereabouts, the opposite could be true and it is as likely that his relatives will give truthful information which may lead to his arrest. Therefore, the investigator should employ his discretion as well as available data on the suspect to analyse the credibility of sourced data. Data obtained from victims can also be useful, as it generally is more credible than data from relatives for the obvious reason that the victim still holds grudges against the suspect. As a result, if the victim has a lead on where the suspect could be hiding, that intelligence is highly likely to be true. The last data source is information obtained from people in the suspect's hometown, people living near the crime scene, or people who live in the area where the suspect used to stay. However, it is not always certain that an investigator can obtain such data as the success rate depend on his or her experience and expertise. Apart from the aforementioned data, other information deemed necessary to the investigation by the ten experts all pertains to the suspect's lifestyle. Examples of such data are financial and banking information, medical service usage, occupation, telephone usage, travelling, various service usages. To rank such information in an order of importance, the researcher has asked the ten experts to identify which of the data they check during investigation. Each type of data will be given a score of 0 to 10 , with 10 being the factor which is always looked up and zero being the factor which is never looked up. The result is shown in the Table 2 .

The Table 2 shows a total of 32 data, all of which are relevant to a suspect's lifestyle after warrant issuance. All of the experts identified these types of data as important to investigation, with social security registration specified as the most useful by all ten experts. Expert 3, Deputy Commissioner, Metropolitan Police Bureau stated that typing the suspect's name into social security database is a surefire way for investigators to find out more about him. The problem with other types of data is their often changing nature, which means that the investigator needs to look them up on a regular basis. For the type of data ranked highly by the experts, the researcher will use these data as a guideline in finding out information on the suspect after warrant issuance. They will be applied to suspects for both offences against body and life, and against property, as they are all relevant to the suspect's lifestyle regardless of the type of offence committed. The limitation of using these 32 types of data is that the location of the suspect can only be roughly determined and cannot be used to pinpoint the exact location. Nevertheless, the information should be a useful starting point for investigation officers in 
searching for information in accrued warrants in the Royal Thai Police, thereby possibly reducing the number of accumulated warrants.

Table 2. Type of data looked up by the experts

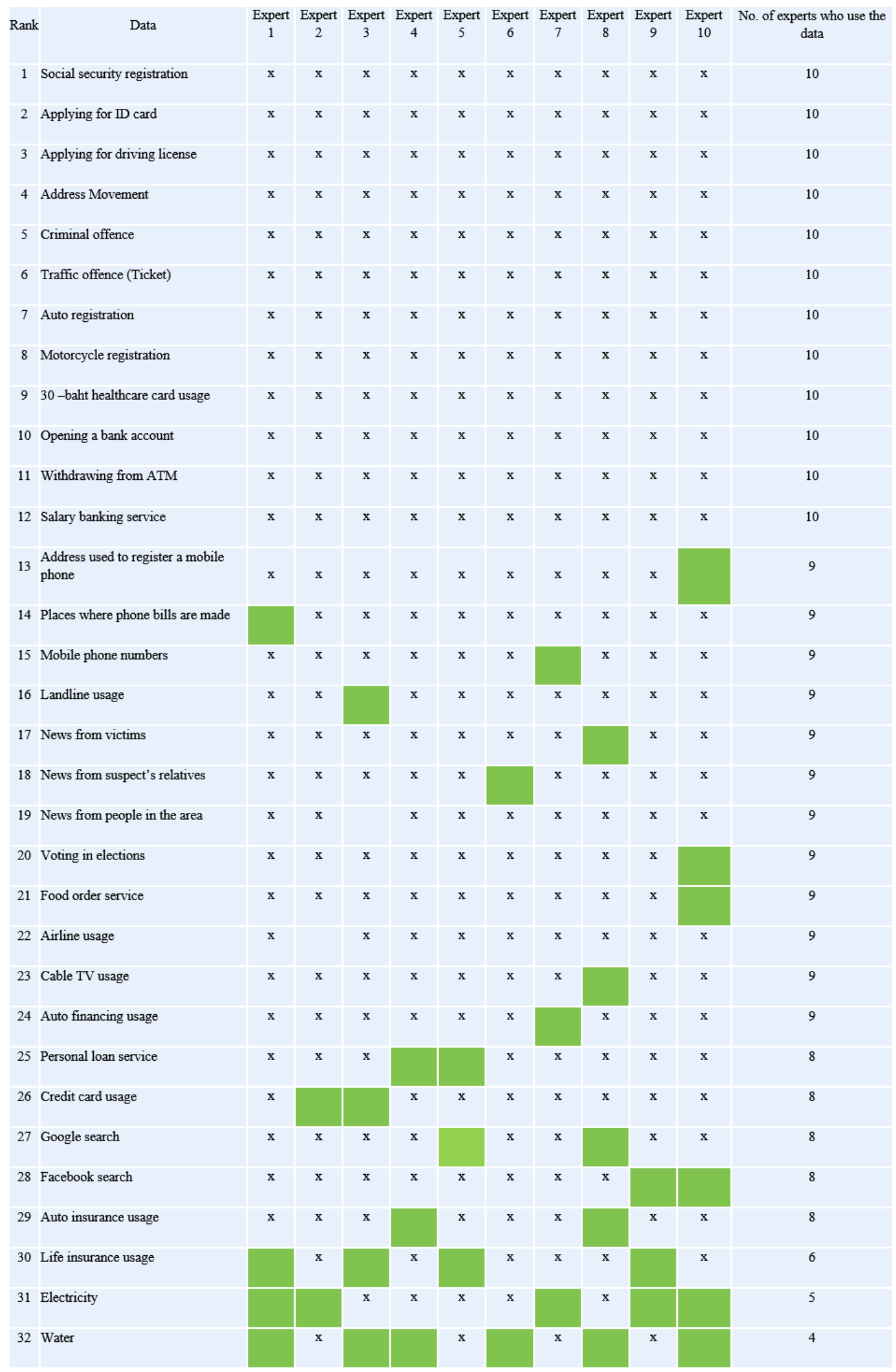




\subsection{Problems and Suggestions}

The first problem is the difficulty in accessing data in all 32 factors. Not all 32 factors can be accessed via POLIS and only some can be looked up on the internet. As for the rest, the investigator will have to rely on personal relationship in attempting to obtain data, the process which may be fraught with difficulty as the agency which possesses the data maybe uncooperative. This will further complicate the investigation and discourage the investigators. The second problem is expenses. Expert 1, Political Deputy Secretary to the Prime Minister gave an example where the suspect who escaped from Nakhon Sawan to Nakhon Sri Thammarat after committing offence. In this case, the Nakhon Sawan police will be responsible for tracking the suspect. In principle, the Nakhon Sawan police will have to contact their counterparts in Nakhon Sri Thammarat to help find the suspect. But in practice, the officers will have to rely on personal relations in coordinating. This is due to the reward system in which the accolade is bestowed upon the office where the warrant is issued, not the office where the actual arrest is made. In this case, even though the Nakhon Sri Thammarat police may have arrested the individual, it is actually the Nakhon Sawan police who have to escort the suspect to prosecute in their province. This will incur significant expenses. Another problem is the lack of cooperation among investigators in each region. This also results in a high number of leftover warrants in the sense that the police station where the offence occurs and the station where the suspect escapes to may not have their information network linked together. The motto, no arrests in the cases that are "not in my backyard" still also persists in Thai police. As for suggestions, the experts all agreed that the most important action which will lead to successful arrest in the most cost effective manner is to complete on-the-table investigation before going to the field. This means finding out information about the suspect as much as possible, verify the information so that it contains little or no errors prior to traveling to the likely areas to make arrest.

\section{Conclusion and Recommendation}

\subsection{Conclusion}

Even though the objective of this research is to study escape behavior of suspects following acts of crime and warrant issuance, the result was that escape behaviour is not as important as the suspects' lifestyle. Therefore, the suspects' lifestyle will be more useful in helping officers track down suspects. According to the experts, there are a total of 32 factors which investigators need to look up, but the factors that are considered more often due to ease of search and high efficiency are: Social security registration, applying for a new identification card, applying for a new driving license, address movement, criminal offence, traffic offence, auto insurance, motorcycle insurance, 30-baht healthcare card usage, opening a banking, withdrawing from an ATM, and salary banking service.

\subsection{Recommendation}

The researcher suggests that a network linking information of all police stations should be developed, especially the 32 important information in which the researchers suggested. This can be done via the POLIS system. By having this network in place, the time spent in searching information by investigating officers can be reduced significantly. Another recommendation is the development of suspect tracking system which compiles relevant information and analyse the likely whereabouts of suspects after acts of crime. This system should also incorporate the aforementioned 32 factors to increase the chance of successful arrests and lead to the reduction in the number of accrued warrants.

\section{References}

Alison, L., McLean, C., \& Almond, L. (2007). Profiling suspects. In T. Newburn, T. Williamson, \& A. Wright (Eds.), Handbook of Criminal Investigation. London: William.

Burgess, J., Douglas, J., \& Ressler, R. (1985). Classifying sexual homicide crime scenes. In T. Newburn, T. Williamson, \& A. Wright (Eds.), Handbook of Criminal Investigation. London: William.

Edwards, C. (2005). Changing Policing Theories for 21st Century Societies. NSW: The Federation Press.

Gill, M. (2005). Reducing the capacity to offend: Restricting resources for offending. In N. Tilley (Ed.), Handbook of Crime Prevention and Community Safety. London: William.

Gudjonsson, G., \& Copson, G. (1997). The role of the expert in criminal investigation. In J. Jackson, \& J. Haugeland (Eds.), Artificial Intelligence: The Very Idea (p. 225). Cambridge: Mit Press.

Newburn, T. (2007). Criminology. Devon: William.

Newburn, T., Williamson, T., \& Wright, A. (2007). Handbook of Criminal Investigation. London: William. 
Rossmo, D. K. (2009). Criminal Investigative Failure. US: CRC Press.

Royal Thai Police. (2013). Crime statistic. Retrieved from http://statistic.police.go.th/dn_main.htm

\section{Copyrights}

Copyright for this article is retained by the author(s), with first publication rights granted to the journal.

This is an open-access article distributed under the terms and conditions of the Creative Commons Attribution license (http://creativecommons.org/licenses/by/3.0/). 